\title{
Joint Research and Development on Toxic- Material Emergency Response Between ENEA and LLNL: 1982 Progress Report
}

\author{
P. Gudiksen, R. Lange, M. Dickerson, T. Sullivan, \\ L. Rosen, and H. Walker \\ Lawrence Livermore National Laboratory, University of California \\ Livermore, California 94550
}

G. B. Boeri, R. Caracciolo, and R. Fiocenza

Comitato Nazionale per la Ricerca e lo Sviluppo

dell'Energia Nucleare e delle Energie Alternative

Rome, Italy

Manuscript date: November 1982

\section{LAWRENCE LIVERMORE LABORATORY} University of California - Livermore, California $\bullet 94550$ 


\section{Contents}

Page

Abstract. ........................ 1 Introduction . . . . . . . . . . . . . . . . . . . 1

Progress During the Past Year ... . . . . . . . . . . . . . 3

Model Development ... . . . . . . . . . . . 3

Multiple Vertical Profiles in the MEDIC/MATHEW Codes. . . . . 3

Space-Variable Surface Roughness and Diffusion Parameters . . . 4

Fine-Resolution Sampling Grid . . . . . . . . . . . . 4

Model Evaluation Studies ................. . 4

Systems Development . . . . . . . . . . . . . 5

ARIES. . . . . . . . . . . . . . . . . . 5

ARAC . . . . . . . . . . . . . . . . . 6

Applications of ARIES and ARAC to Simulated or Actual Emergencies . - 7

ARIES Response at Caorso . . . . . . . . . . . . . . . 7

ARAC Feasibility Study . . . . . . . . . . . . . . 7

Radiological Measurements . . . . . . . . . . . . . 8

ARIES Activities . . . . . . . . . . . . . . . . . 8

ARAC Activities . . . . . . . . . . . . . . . 8

Data Base Development. . . . . . . . . . . . . . . . 9

Supporting Meteorological Field Experiments ...........10

Future Cooperative Studies . . . . . . . . . . . . . . . . . 11

Model Development . . . . . . . . . . . . . . . .11

Space-Variable Surface Roughness and Stability . . . . . . . . . .11

Transfer of Models to Minicomputers . . . . . . . . . . .11

Rainout and Washout. . . . . . . . . . . . . . .11

Deposition . . . . . . . . . . . . . . . .11

External Dose Module . . . . . . . . . . . . . . . . . .

Pl ume Rise Formulation . . . . . . . . . . . . . . . . . .12

Building Wake Effects . . . . . . . . . . . . . 12

Model Evaluation. . . . . . . . . . . . . . . . . . .12

Standardization of Model Input Parameters . . . . . . . . . . 12

Systems Development. . . . . . . . . . . . . . . . . 13

Real-Time Utilization of Radiological Measurements and Model

Calculations . . . . . . . . . . . . . . . 13

Supporting Field Experiments . . . . . . . . . . . . . 14

References 


\title{
Joint Research and Development on Toxic Material Emergency Response Between ENEA and LLNL: 1982 Progress Report
}

\begin{abstract}
This report provides a summary of current and future cooperative studies between ENEA and LLNL researchers designed to develop improved real-time emergency response capabilities for assessing the environmental consequences resulting from an accidental release of toxic materials into the atmosphere. These studies include development and evaluation of atmospheric transport and dispersion models, iriterfacing of data processing and communications systems, supporting meteorological field experiments, and integration of radiological measurements and modei results into real-time assessments.
\end{abstract}

\section{Introduction}

During the past decade, the Lawrence Livermore National Laboratory (LLNL) has developed the Atmospheric Release Advisory Capability (ARAC) for providing real-time assessment of the consequences of an accidental release of radionuclides into the atmosphere. This capability, developed under the auspices of the U. S. Department of Energy (DOE), has been of considerable interest both to numerous $U$. S. federal, state, and local agencies and to the U. S. nuclear power industry. This U. S. interest has recently broadened to an international scale. In collaboration with LLNL, the Italian Comitato Nazionale per la Ricerca e lo Sviluppo dell'Energia Nucleare e delle Energie Alternative (ENEA) in Rome is currently working on the design and implementation of ARIES (Accidental Release Impact Evaluation System), a somewliat similar real-time emergency response and assessment capability that utilizes the ARAC MEDIC/MATHEW/ADPIC atmospheric transport and diffusion codes. This report summarizes the on-going cooperative studies by ENEA and LLNL designed to improve and strengthen their respective emergency response capabilities.

These cooperative studies were initiated when ENEA requested, through the DOE, copies of the MATHEW/ADPIC computer codes. In order to become more familiar with the codes, several ENEA staff members visited LLNL during August 1980 for detailed discussions with the ARAC staff. The ENEA scientists could then transfer the codes to their IBM computers.

In May 1981, ENEA organized a joint workshop in Rome with LLNL staff members. The purpose of this workshop was to show the LLNL representatives more about ENEA's overall emergency response and assessment responsibilities, assist with implementing the MEDIC/MATHEW/ADPIC codes into ARIES, and determine if further mutual cooperation would be beneficial. A seminar was conducted to inform various Italian governmental agencies and other members of the European nuclear community about ARAC and its uses in the U.S. and about the current status of ARIES and its proposed utilization in support of the Italian nuclear power program. In addition, a joint research program was formulated to enhance further development of the ARIES and ARAC systems. To ensure that this 
cooperative effort remains productive for the next several years, it was agreed that members of ENEA and LLNL would exchange visits on an annual basis. In consonance with this agreement, an ENEA meteorologist participated in the DOE-sponsored Atmospheric Studies in Complex Terrain (ASCOT) field studies in northern California during August 1981, for the dual purposes of acquiring data for model evaluation and gaining expertise in the planning and implementation of similar field studies in Italy in support of ARIES development. During May 1982, several ENEA and LLNL representatives attended the next workshop at LLNL, for further detailed discussions regarding computer codes, the continued development of the ARIES and ARAC emergency response systems, and the initial coastal meteorological field experiments conducted in Italy. At this time a seminar was presented to the LLNL staff on emergency response planning in italy with special emphasis on the application of the ARIES capability to a simulated accident at the Caorso Nuclear Power Plant in northern Italy. In August 1982 an ENEA representative visited LLNL to familiarize himself with the new ARAC operating system that is scheduled to become operational in early 1983. An LLNL staff member visited ENEA during September 1982 to discuss a broad range of emergency-response topics and their implications for future improvements by both organizations.

Because both the ARIES and ARAC systems are making the transition from the research to the operational phase, the associated research efforts will be directed toward improving their present assessment capabilities. The workshop discussions have identified several areas requiring additional research. There are three major areas of mutual interest:

1. Further development of the MEDIC/MATHEW/ADPIC models by both ENEA and LLNL staff members. This includes improving the methodologies for estimating close-in doses, plume rise and building wake effects, rainout and washout, deposition, and space-variable surface roughness.

2. Further evaluation of the MEDIC/MATHEW/ADPIC models using meteorological and tracer data acquired from field experiments conducted by several Italian meteorological organizations at a coastal site north of Rome. These experiments promise to yield data that will be valuable to both LLNL and ENEA scientists, especially because the models have not been thoroughly evaluated for coastal meteorological conditions. Likewise, the ASCOT experiments conducted in California and Colorado will provide data to both organizations that will be useful in evaluating the models in complex terrain settings.

3. Improve the confidence levels of the ARAC and ARIES assessments by (1) standardizing of the values used for the model input parameterizations, and (2) investigating appropriate methods for integrating the radiological measurements with the model predictions.

These tasks represent a considerable level of effort and cannot readily be undertaken by either organization alone. However, by combining efforts and sharing information on a regular basis, the LLNL and ENEA can perform the work within existing programs in the two organizations. At the May 1982 workshop at the LLNL, participants assigned priorities and the organization responsible for 
performing specific tasks, and preliminary plans were formulated for LLNL representatives to meet with members of the ENEA staff in Rome some time during 1983 to discuss technical progress in high-priority areas. At that time, ENEA will also organize a meeting with members of the European Nuclear Community to share information concerning the ARAC and ARIES capabilities with nuclear emergency-response personnel throughout Western Europe. It was also agreed that an LLNL representative might participate as an observer in the Italian coastal meteorological field studies during 1983.

The remainder of this report summarizes the progress accomplished during the past year as part of this cooperative arrangement and expands the description of specific tasks to be undertaken during the next several years.

\section{Progress During the Past Year}

\section{Model Development}

The main components of the ARAC (and ARIES) computer models are the interpolation code MEDIC, the mass conservative wind field code MATHEW, and the transport and diffusion code ADPIC. Model development on all three codes continued during the past year, but not all changes have yet been incorporated into the operational versions of the codes, because further testing of the correctness of these changes is required. The following provides a description of the mode] development activities undertaken by the ARAC staff during the past year.

\section{Multiple Vertical Profiles in the MEDIC/MATHEW CODES}

The MEDIC/MATHEW codes provide the mean wind field for the ARAC (and ARIES) models. Originally, MEDIC provided a three-dimensional wind field of horizontal winds based on horizontal interpolation of surface station wind data and vertical interpolation of only one vertical wind profile for the whole grid. MATHEW then computed the vertical wind field components by introducing topography and mass adjustments to obey the continuity equation.

In the application of the these models to the complex terrain situations encountered in the ASCOT program, it became evident that a single vertical profile is not sufficient to describe the wind field over a $10-\mathrm{km}$ grid, especially when several vertical profiles e measured by tethersondes or acoustic radars. Consequently, the MEDIC/MATHEW codes were improved to accept up to 15 vertica] profiles.

With this improvement, MEDIC first interpolates horizontally not only the surface measurements but also the multiple vertical profiles at the various grid levels above terrair then it ties the two types of measurements together by vertical interpolation. In addition, the terrain is now introduced in MEDIC, so that MATHEW only has to impose conservation of mass and produce the vertical velocity components. When new multiple-profile versions of MEDIC/MATHEW were tried out on an ASCOT data set with eight vertical profiles, the result was a much-improved wind field when compared with measurements. 


\section{Space-Variable Surface Roughness and Diffusion Parameters}

The surface roughness, parameterized by a surface roughness height $\left(\mathrm{z}_{0}\right)$ in the models, is important because it affects the vertical wind profiles and the values of the diffusion coefficients. It has become evident that sea breeze and complex terrain models need to have the capability to include a spacially varying roughness height. Even though the MEDIC/MATHEW/ADPIC models cannot compute internal boundary layers created by a change in $\mathrm{z}_{0}$, such a change affects the logarithmic wind profiles and the ADPIC diffusion parameters.

LLNL has modified the ADPIC model to accept a two-dimensional array of surface roughness height in order to compute a two-dimensional array of friction velocities $U *(i, j)$, which in turn make the horizontal and vertical diffusion coefficients $\mathrm{K}_{\mathrm{h}}$ and $\mathrm{K}_{\mathrm{z}}$ a function of horizontal location. Because the diffusion coefficients were already a function of height, this makes them fully three-dimensional variables.

The two-dimensional array of surface roughness heights car be created from aerial photographs and/or site surveys. Because of the limited resolution of the codes, values averaged over the size of the cells are sufficient. The values should reflect not only the height and density of the vegetation but also the subgrid topographical features such as gulleys and ridges.

\section{Fine-Resolution Sampling Grid}

One of the biggest problems with grid-mesh models is that in the vicinity of a "point" source, the calculated concentration field is not well resolved. Generally, whenever the plume is small compared with a grid cell, the derived concentrations are too low. Thus, even though the wind field used by the ADPIC code is usually well resolved by one grid cell, and the particle diffusion is treated by the source particle treatment on the subgrid scale, the concentration field produced by the model suffers from this close-in resolution problem. To resolve this problem, the ADPIC model and the contour plotting code PDO have been modified to compute and display selected concentration sampling arrays whose cells are submultiples of the standard computational grid cell. This provides improved resolution of the close-in concentrations (by a factor of eight for halving the standard ADPIC grid cell in each dimension); however, the computational storage and time requirements increase rapidly with this method. In addition, the resolution of the topography does not increase with this scheme because it is based on the computational grid cell size and not on the sampling cells. Modeling studies using these models in complex terrain indicate that increased resolution of topography is important in the close-in calculation, and that it must be included in further development.

\section{Model Evaluation Studies}

Model evaluation efforts at LLNL during the past year were devoted to coinparing the results of the MEDIC/MATHEW/ADPIC calculations with the tracer and meteorological data acquired during the 1980 ASCOT field studies in The Geysers geothermal area in northern California. These studies consisted of five separate and identical experiments. Each experiment included the release of five inert gaseous tracers into the nocturnal drainage flows generated over the roughly 
7-km by $10-\mathrm{km}$ study area. The measured surface concentration patterns and the vertical profiles of tracer concentrations, along with the extensive meteorological measurements networks, provided the data base currently in use for the model validation studies. Using a $250-\mathrm{m}$ horizontal and a $50-\mathrm{m}$ vertical model grid resolution, the model calculations agree reasonably well with the measured tracer concentration patterns. Comparisons of individual concentration measurements in space and time with the cell-averaged results from the calculations were within a factor of five for $75 \%$ of all the measurements however, agreement within a factor of two occurred for only $30 \%$ of the measurements. This is a reasonable expectation in view of previous experience using data acquired in more gentle terrain situations where agreements between calculations and measurements have generally proven to be within a factor of three. 1 In complex terrain, however, model grid resolution presents a formidable problem for the modeler. The problem appears to be most severe close-in to the source and in areas where local topographic effects play a dominant role in the transport and dispersion processes, because point location measurements of tracer and meteorological data must be compared with the model's grid cell volume averages. In addition, calculations indicate that the diffusivity parameters in complex terrain are larger by a factor of two to five than the equivalent values over flat terrain.

\section{Systems Development}

The following outlines the current status of ARIES realization program and the ARAC expansion program.

\section{ARIES}

In the event of an accidental release of a hazardous material into the atmosphere, the ARIES will have the capability both of providing real-time estimates of the hazards to downwind population centers by integrating model calculations with on-site measurements and of recommending suitable countermeasures to minimize the impact of the accident. 2 To provide this service, an emergency center (CEC) has been established at ENEA Headquarters in Rome. The CEC serves as the focus of ARIES operations during an emergeney. When it is fully equipped, it will be linked by both voice and data telecommunications with the Servizio Meteorologico dell'Aeronautica (Italian Air Force Weather Service), supporting ENEA radiological measurement laboratories, user sites, subsidiary operations centers, etc. This will enable the CEC to collect the meteorological, radiological, and source emissions data needed for the hazards evaluations to be collected at the CEC for subsequent processing using a resident minicomputer and associated data processing and display systems. The computer codes used for the hazards evaluations include simple analytical models that can be operated by the minicomputer and the three-dimensional MEDIC/MATHEW/ADPIC models, which must be run on the ENEA central computer system.

Within the CEC, there are currently three basic hardware components performing the following functions:

1. A system console that manages all of the operational aspects of an emergency such as data collection, processing, and display 
2. A processing facility for operating the data transmission network and executing the simpler codes

3. Two interactive facilities that provide detailed information and analyses by means of graphical presentations of wind fields and plume shapes

During the past year, these three basic components were acquired and made operational. In addition, the communications network between the $\mathrm{CEC}$ and the ENEA computer center was established this network permitted the MEDIC/MATHEW/ADPIC codes to be adapted to the ARIES.

ARAC

During the past year, the ARAC staff developed and published ${ }^{3}$ a set of systems requirements suitable for the planned expansion of the ARAC system. These requirements spelled out a need for improved performance in all areas of the ARAC system. Of particular importance were the needs for improved and increased data communication, standardization of data formats, improved data basing and archiving, easier operator interaction, improved and expanded graphics, automation of manual tasks, and consolidation of the entire ARAC response system on the computer system. A major design effort was initiated within ARAC's engineering and programming staffs to convert existing software or to develop new sof tware as needed and to determine the hardware requirements necessary to satisfy the design criteria for the upgraded system. The participating staff members were trained in the Yourdion approach to "structured analysis, design and programming"; this approach was established as the fundamental sof tware development methodology. Fortuitously, a commercial venture offered to fund a conversion effort to develop A merican National Standards Institute A merican $\mathbf{N}$ ational Standards Institue (ANSI) standard FORTRAN 77 versions of the ARAC models for 32-bit computers. This accelerated development of the new ARAC software system and provided an opportunity to "benchmark" a new DEC VAX 11/782 dual-processor computer as a candidate hardware system.

In late June 1982, the ADPIC model conversion was completed and used as a benchmark on a VAX 11/780. The results demonstrated that a system based on a VAX 11/780-782 can provide sufficient computational capability to meet the ARAC requirement of an ADPIC model calculation within $45 \mathrm{~min}$ of notification of an emergency. An order has been placed for one complete VAX 11/782 with a high probability of an upgrade of the present VAX 11/780 to an 11/782 in the next fiscal year. This hardware system will provide a software/operations environment in which real-time data collection and transmission can occur simultaneously with model input generation, rapid (and extensive) color graphics display, and concurrent model execution. The ARAC response system will integrate several major software packages (both LLNL and DEC) within a "problem/response manager" operating system being developed to automatically request, assemble, and display all pertinent data, control model execution, and final output display. The new ARAC response system is planned for implementation in January 1983. 


\section{Applications of ARIES and ARAC to Simulated or Actual Emergencies}

During February 1982, the first significant application of the ARIES concepts to a simulated emergency situation was made during an exercise at the Caorso Nuclear Power Plant situated at Piacenza in northern Italy. During the previous year, the ARAC had responded to more than 20 exercises or situations involving the potential release of hazardous materials into the atmosphere. The ARlES response at Caorso is; described below, followed by a summary of a study addressing the feasibility of utilizing the ARAC service at all U.S. nuclear power plants and the $\mathbf{5 0}$ state offices of emergency preparedness.

\section{ARIES Response at Caorso}

The technical scenario used in this exercise was developed by ENEA personnel; it utilized all components of the ARIES system. 4 Exercise participants included the local prefect, army, police, civil defense forces, local government agencies, and the electricity generating board (ENEL) that operates the nuclear power plant. Using meteorological data from the power plant that characterized the most typical flow patterns over the region, the ARIES version of the MEDIC/MATHEW/ADPIC codes was utilized to precalculate a series of most likely dose and surface contamination patterns that could result from the exercise scenario. A subset of these patterns was then chosen to best represent the meteorological situation during the seven-hour exercise. These patterns included air concentrations and surface contamination levels of $13 \mathrm{l}_{\mathrm{I}}, 85 \mathrm{Kr}, 88 \mathrm{Kr}$, $133 \mathrm{Xe}$, and $135 \mathrm{Xe}$, along with the appropriate conversion factors relating the data to the specific radiation detection devices utilized by the radiation monitoring teams in the field.

\section{ARAC Feasibility Study}

This study, which was designed to evaluate the feasibility of expanding the ARAC services to the nuclear power industry and state governments on a national scale, involved the installation of ARAC site systems at two nuclear power plants and the associated state offices of emergency preparedness. These were the Indian Point Nuclear Power Station in New York State, the New York State Office of Emergency Preparedness, the Rancho Seco Nuclear Generating Station in California, and the State of California Office of Emergency Services. These site systems have the capability of acquiring and processing local meteorological data and transmitting these data to the ARAC Center at LLNL as well as receiving and displaying the MEDIC/MATHEW/ADPIC calculations. In order to familiarize the users with the ARAC service, a training program was instituted that included formal meetings at LLNL and on-the-job training incorporating a series of four exercises. Upon completion of this training program, users appeared to be competent to use the ARAC service effectively in the event of an emergency. This training was put to use in January 1982 during the Ginna nuclear power reactor accident when the ARAC staff and personnel from the New York State Office of Emergency Preparedness quickly combined resources to assèss the consequences of the accident. 


\section{Radiological Measurements}

The importance of integrating the radiological measurements with the model calculations in order to improve hazards evaluations is well recognized within the ARIES and ARAC programs. During the past year the ARIES staff has concentrated on formalizing a protocol that will allow real-time analysis of the radiological measurements acquired by the field survey teams and comparison with the ARIES model calculations The main emphasis within the ARAC program has been on standardizing the radiological units used for reporting the measured values.

\section{ARIES Activities}

In the event of a nuclear power plant accident in Italy, radiological survey teams and assay laboratories are deployed by the utility, the national fire department, ENEA, and the local governmental authorities. Their mission is to define the temporal and spatial distributions of the released radioactivity in the environment surrounding the affected power plant. These teams are equipped with a variety of radiation detectors that include Geiger-Mueller (G-M) counter's, scintillation detectors, ionization chambers, and thermoluminescent dosimeters. In addition, airborne scintillation detectors may be used for large area surveys.

It is quite difficult to make clear comparisons of the measurements obtained by this variety of radiation detectors and to integrate the data with the ARIES calculations. To facilitate this process, the ARIES staff is currently developing an Instrumentation Data Bank that will contain data on performance characteristics of radiation detectors, intercalibration factors, measurement procedures, and environmental sample collection and analysis techniques.

\section{ARAC Activities}

The primary focus of the ARAC efforts in this area during the past year was on standardizing the radiological units used by the various Department of Energy emergency response groups. The units that were agreed upon are listed below:

Description

Source Term

Instantaneous release

Continuous release

Air Concentrations

Instantaneous

Integrated

\section{Deposition}

Gamma emitters

Nongamma emitters

${ }^{239} \mathrm{Pu}$ (dispersal calculations)
Unit

$\mathrm{Ci}$

$\mathrm{Ci} / \mathrm{s}$

$\mathrm{Ci} / \mathrm{m}^{3}$

$\mathrm{Ci} \cdot \mathrm{s} / \mathrm{m}^{3}$

$\mathrm{R} / \mathrm{h}$ at $1-\mathrm{m}$ height

$\mathrm{Ci} / \mathrm{m}^{2}$

Alpha activity $\left(\mathrm{Ci} / \mathrm{m}^{2}\right)$ 
${ }^{239} \mathrm{Pu}$ (aerial measurements) -

$\left({ }^{241} \mathrm{~A} \mathrm{~m} /{ }^{239} \mathrm{Pu}\right.$ known)

${ }^{239} \mathrm{Pu}$ (aerial measurements) -

$\left({ }^{241} \mathrm{~A} \mathrm{~m} /{ }^{239} \mathrm{Pu}\right.$ unknown)

Dose Equivalent

Dose Conversion Factors

ln ternal

External

Particle Size Distribution (Lognormal)

Activity mean aerodynamic (AMA) diameter

Geometric standard deviation

\section{Other}

Specific activity

Deposition velocity

Wind speed

Wind direction

Breathing rate (standard man)
Alpha activity $\left(\mathrm{Ci} / \mathrm{m}^{2}\right)$

$\mathrm{Ci} / \mathrm{m}^{2}\left(24 \mathrm{l}_{\mathrm{Am}}\right)$

Rem

$\mathrm{Rem} / \mathrm{Ci}$ inhaled

$\frac{\mathrm{Rem} \cdot \mathrm{m}^{3}}{\mathrm{C} \cdot \mathrm{s}}$ or $\frac{\mathrm{Rem} \cdot \mathrm{m}^{2}}{\mathrm{Ci}}$
Micrometer at unit density
$\mathrm{Ci} / \mathrm{g}$ of isotope of interest

$\mathrm{m} / \mathrm{s}$

$\mathrm{m} / \mathrm{s}$

Degrees from true north

$20 \ell / m$

\section{Data Base Development}

An integral part of any reartime emergency response system is the data basing and manafement systems that permit the rapid extraction of pertinent data needed during an emergency. During the past year, the ARIES staff has developed such a system containing significant information related to the siting of nuclear power plants. The methodology is based on the superposition of a $1-\mathrm{km}^{2}$ grid mesh over the entire country. Each grid is assigned an n-component vector, in which each component is associated with a particular parameter. These parameters include data on seismicity, topography, hydrology, slope of coastline topography, and population data. The system is capable of rapid data retrieval with subsequent computer-generated color grephical displays including multiple overlay; if desired.

The ARAC staff has recently completed a rapid terroin retrieval system that is capable of generating ARAC model-compatible terroin files for any location within the continental U.S. during an emergency situation. This system, which has been available since early 1982, has been exercised numerous times and has demonstrated the system's reliability and effectiveness. This system of codes and data bases was designed and implemented during 1981 with an initial response capability available during the summer of 1981 and a gradual augmentation to the full system during the rest of that year. In an accident situation the only 
information required to run the system is the location of the accident (in latitude, longitude or Universal Transverse Mercator [UTM] coordinates). The system extracts the required data from the ARAC-averaged terrain data base and ereates the specified ARAC terrain file in three to five minutes. Additional time is required to graphically examine the output for validation purpcses. Thus, typically five to ten minutes are needed to extract the data during an emergency situation. The output from this system, a standard ARAC terrain file, contains the terrain data for a 400-by-400 array of square grid cells. The file contains an array of values, with each value being the average height, in meters, of the correspo ting grid cell. The grid is oriented along the UTM grid system for the specificd location. Because the grid cells are typically $500 \mathrm{~m}$ by $500 \mathrm{~m}$, the total area described by the file is $200 \mathrm{~km}$ by $200 \mathrm{~km}$. The ARAC-averaged terrain data base, used as the data source for the terrain system, was designed to minimize the computations that must take place during a response and to be small enough to be aceessible within a very few minutes. This data base was generated from higher resolution data acquired from the National Cartographic Infoulation Center (NClC) in Reston, VA. 'l'ne terrain system is currently being expanded to make this much larger data base directly accessible, although not in as timely a fushion, to allow building of terrain files for special problems and assessments.

\section{Supporting Meteorological Field Experiments}

Both ENLA and LLNL were involved in conducting field studies to acquire the data needed to increase our knowledge of pollutant transport and dispersion processes associated with specific flow phenomena. Because of its interest in the possibility of siting nuclear power plants in constal areas, ENEA conducted t wo sea breeze experiments at a coastal site near Montalto di Castro, which is situated 75 $\mathrm{km}$ north of Rome. 'lhese experiments were designed to cvaluate the characteristics of the boundary layer during typical sea breeze situations. Initit] results reveal an internal boundary layer that reaches $6-7 \mathrm{~km}$ inland and is shaped like a parabolic are. At noon the boundary layer heig!ts were about $100-200 \mathrm{~m}$ on the coast and about $400-500 \mathrm{~m}$ at $a$ distance of $6 \mathrm{~km}$ inland. The wind speed maximum occurred at a height of 150-200 $\mathrm{m}$ above the surface.

The LLNL was involved in a series of ASCOT field experiments during the past year. The specific objective of the ASCOT program has been to study the transport and dispersion of pollutants entrained in nocturnal drainage flows, using The Geysers geothermal area in northern California as the study site. During August 1981, a series of experiments was conducted to acquire the data needed to evaluate existing cooling tower plume models and atmospheric transport and dispersion models in order to improve our capabilities for predicting the impact of the $\mathrm{H}_{2} \mathrm{~S}$ emissions from future geothermal power plant cooling towers during nocturnal drainage flows and daytime limited vertical mixing periods. These two meteorological scenarios have been identified as situations that may lead to potential air quality impacts. The experiments included measurements from perfluorocarbon tracer releases, airborne lidar observations, and surfaced-based time-lapse photography of the cooling tower plume characteristics as well as measurements from a variety of meteorological instruments such as acoustic sounders, tethersondes, meteorological towers, and laser anemometers. 


\section{Future Cooperative Studies}

\section{Model Development}

As the ARAC and ARIES systems are applied in an increasing diversity of emergency situations, the need for additional modeling capabilities has become evident. The areas of principal interest from a modeling improvement point of view are listed below, along with the primary organization responsible for performing the work. In addition: :ne high-priority tasks are denoted accordingly.

\section{Space-Variable Surface Roughness and Stability (LLNL; Priority 1)}

Variable-surface-roughness height has been included in ADPIC, but it will also have to be included in the MEDIC/MATHEW codes because of its important effect on the wind profiles and slip velocities at the surface. This, by itself, is not a major modification; however, it does require that horizontally and vertically space-variable prescription of the MATHEW mass adjustment parameters (sigmas) be available to account for sea-land transitions and variations in vertical stability. Prescription of these sigma parameters in MA'THEW is highly empirical and is likely to remain this way for some time.

\section{Transfer of Models to Mini-computers (LLNL; Priority 1)}

The LLNL has begun to transfer the MEDIC/MATHEW/ADPIC codes to the VAx-1 1/780 minicomputer, with the intent of providing the full ARAC services via the VAX. Such a transfer offers complete freedom from the time-shared LLNL CDC-7600 computer system by performing all of the data processing and model calculations on an ARAC-owned VAX computer. The principal disadvantage of this transfer is the VAX's slower computational speed, caused in part by its smaller in-core memory. The transfer requires that the codes be translated into ANSI standard FORTRAN 77 from the LLNL-developed LLTRAN.

\section{Rainout and Washout (LLNL)}

For the regional aspects of the ARAC requirements, there is at present no intention to address in-cloud rainout. However, the present rudimentary below-cloud washout module in ADPIC will be updated to be more versatile. This will permit washout to occur only over selected parts of the grid for selected time periods. This requires that the code compute surface deposition as a function of particle size, rain rate, space, and time.

\section{Deposition (LLNL)}

Wet and dry deposition is computed in ADPIC as a function of particle radius and/or by specifyiring a deposition velocity at the surface. Because of the computer limitation on the total number of ADPIC marker particles permitted in the grid, deposition of whole marker particles of ten results in a noisy deposition contour pattern because not enough of the particle is deposited on the surface. To resolve this problem, the marker particle deposition prosesses will be modified to permit partial deposition of individual marker particles, thus providing smoother patterns. 


\section{External Dose Module (ENEA)}

At present, the external dose to an individual during cloud passage is estimated by applying a dose conversion factor to the integrated surface air concentrations derived by the ADPIC code. An effort will be made during the coming year to investigate the possibility of including a more realistic technique based on summing up the contribution to the external dose from the individual ADPIC marker particles.

\section{Plume Rise Formulation (ENEA)}

Because accidental releases of radiation into the atmosphere from nuclear reactors of ten involve plume rise resulting from buoyancy as well as mechanically induced effects, there is interest in comparing the results of the current plume rise formulations with experimental data.

\section{Building Wake Effects (ENEA)}

Because nuclear power plants are situated close to population centers in ltaly, building wake effects may be important during an emergency situation for estimating the radiation doses to people within the first kilometer of the plant. Experimental data acquired from the literature will initially be used to assess the magnitude of these effects, and an assessment will be made in regard to the leasibility of including these effects in the model calculations.

\section{Model Evaluation (LLNL; Priority 1)}

Extensive tracer and meteorological data sets have been acquired by the ASCOT program for nceturnal draingge flow situations in The Geysers area during the past three years. A considerable effort is currently underway at $I, L N L$ to validate the MEDIC/MATHEW/ADPIC models by means of these data. This effort will continue during the coming year and will concentrate on the interaction of cooling tower plumes with the nocturnal drainage flows. In addition to these data, the ARAC staff will also utilize the sulfur hexafluoride and oil fog tracer data and meteorological data acquired within the upper Snake River plain in Idaho during July 1981 for inodel validation purposes. These experiments included a sulfur hexafiuoride surface sampling network out to a distance of $72 \mathrm{~km}$ from the release point and an airborne lidar system for oil fog detection. During the coming year, the ARAC staff will be comparing the ARAC real-time predictions made during the experiments with the actual measurements.

Because the MEDIC/MATHEW/ADPIC models have not been applied to sea breeze situations, the ENEA staff will be evaluating the models by utilizing the sea breeze flow field data acquired at the coastal study site north of Rome.

\section{Standardization of Model Input Parameters (LLNL and ENEA; Priority 1)}

To ensure rapid real-time responses during emergency situations, careful and complete documentation of the model input requirements is necessary. Using the present model input parameter files as a starting point, the ARAC and ARIES staff meinbers plan to document each input parameter in regard to its function and range of values for particular situations. This will take the form of a brief deseriptive 
summary, based on literature searches and past experience, to define the model input parameters that are needed within each of five elements of a typical assessment problem: (1) site characteristics, (2) meteorological ' 3 ta, (3) source characteristics, (4) pollutant behavior, and (5) dose conversion.

\section{Systems Development (ENEA and LLNL; Priority 1)}

Further development of the ARIES system during the next several years will be focused on four efforts: (1) complete implementation of the hardware configuration of the emergency center, (2) implementation of the telecommunications network, (3) initiation of the operational phase, and (4) possible conversion from IBM to DEC VAX computers.

During the coming year ARAC operations will undergo a complete changeover of hardware and sof tware as part of an upgrade to meet the expanded requirements. The current PDP $11 / 40$, PDP $11 / 34$, and HP minicomputers and associated communications, data collection, display, and archive functions will be replaced by expanded and more capable functions on a dual VAX 11/780 - 11/782 systen. The aging site system PDP $11 / 04 s$ will also be replaced with the very recently announced DEC PC 300-class computer. All systems will incorporate color graphics, including hardcopy, multitask performance, rapid response, and standardized user interaction semantics. A phased implementation is planned with a one-for-one replacement of current capabilities during the winter, replacement of old site systems by late winter, enhanced automation of the emergency response process by spring, and a utomated response report generation by the summer of 1983. In addition, a major improvement will result from the transfer and integration of the ARAC models from the CDC 7600 s to the VAX 11/782. This will be completed during the spring of 1983. Completion of these improvements will permit the entire ARAC response to be prepared and managed on the single VAC $11 / 782$ system. Dual machines will be installed for total hardware backup.

\section{Real-Time Utilization of Radiological Measurements and Model Calculations (LLNL; Priority 1)}

The principal reason for employing radiological measurement systems and numerical nodels during an accidental atmospheric release of toxic material is to minimize the radiological hazards to the population near the accident site. It is also important to document the total exposure during and after the accident to enable both realtime and post-accident procedures to be implemented for mitigating the effects of various exposure levels.

The concept of this section is to integrate the radiological measurements with the numerical model calculations rather than to use each as an independent resource in order to maximize the information available for emergency response planning and implementation. By properly combining both resources, a more complete and accurate description of the accident consequences can be determined than if they are used with minimal interaction between the two resources. Properly integrated for implementation during an emergency, the resources can be used to (1) estimate the amount released, (2) provide upper and lower bounds on population exposures, and (3) provide rear-time and post-accident exposure levels. This information can be used to help formulate protective action guidelines based on the best available information. 
In addition to providing improved information in a coupled mode, the integrated resources increase confidence and expand the capability of each. Once an operational confidence level has been established during an accident, through comparisons and checks between model results and measurements, model calculations can be used to position measurement teams and increase the probability that they will be able to understand the concentration pattern. Finally, confidence in model calculations allows for extrapolating the measurements over large areas where detailed measurements are not feasible.

Four elements are required to interface model calculations and radiological measurements: (1) an efficient rechanism for data basing and retrieving the measurements, (2) predetermined measurement techniques that allow comparisons between various measurement sy.stems and between measurements and model calculations, (3) predetermined rnodel calculations that are computible with comparisons to measuremeniti, and (4) an efficient and versatile mechanism for displaying model calculations and measurements that meets the objectives established for their coupled usaje.

During the coming year, guidelines will be established and techniques will be proposed for coupling modeling calculations with radiological measurements during an emergency. These will include (1) guidelines for deploying measurement teams that provide data that are suitable for comparison with model calculations; (2) analytical techniques that permit rapid comparisons between measurements and calculations; and (3) the methodology for real-time data basing, retrieval, analysis, and displny needed to support the above functions. Several examples will be presented to illustrate the implementation of the proposed methodology.

\section{Supporting Field Experiments (LLNL and ENEA; Priority 1)}

The ASCOT field experimental program has veen transferred from The Geysers geothermal area to the oil shale regions of western Colorado. A series of experiments was recently undertaken in this new study area to gain initial insight into the behavior of the flows that are characteristic of this region and to gain experience with the logistical aspects of carrying out field studies in this area. These studies were based on three experimental designs related to valley flows and regional scale flows throughout the entire diurnal cycle. During the coming year, the focus will be on completing the data processing and analysis phases of this work prior to initiating the design of follow-on experiments.

A series of sea breeze field studies will be conducted in Italy during the coming year. The purpose of these studies will be to evaluate the transport and dispersion processes related to pollutants entrained within the land-sea flow regimes. The tracer and meteorological data acquired in these studies will be utilized to evaluate the applicability of the MATHEW/ADPIC models to sea breeze regimes. 


\section{References}

1. R. Lange, "ADPIC - A Three-Dimensional Particle-in-Cell Model for the Dispersal of Atmospheric Pollutants and Its Comparison to Regional Tracer Studies," J. Appl. Meteor., 17, (3), 320-329 (March 1978).

2. CNEN-DISP: ARIES - lst Progress Report, RTI-AMB (October 198I).

3. T. J. Sullivan, ARAC VAX System Design Criteria, Lawrence Livermore National Laboratory, Livermore, CA., Report UASG 82-1 (January 1982).

4. CNEN-DISP: Esercitazione del Piano di Emergenza esterna per la centrale elettronucleare di Caorso - 9 Febbraio 1982. Scenario dell'evoluzione dell'incidente, RTI-DISP(82).

0100E 